\title{
THE COST-EFFECTIVENESS OF PERMETHRIN-TREATED BED NETS IN AN AREA OF INTENSE MALARIA TRANSMISSION IN WESTERN KENYA
}

\author{
VIRGINIA WISEMAN, WILLIAM A. HAWLEY, FEIKO O. TER KUILE, PENELOPE A. PHILLIPS-HOWARD, \\ JOHN M. VULULE, BERNARD L. NAHLEN, AND ANNE J. MILLS \\ Health Economics and Financing Programme \& Gates Malaria Partnership, London School of Hygiene and Tropical Medicine, \\ London, United Kingdom; Division of Parasitic Diseases, National Center for Infectious Diseases, Centers for Disease Control and \\ Prevention, Atlanta, Georgia; Centre for Vector Biology and Control Research, Kenya Medical Research Institute, Kisumu, Kenya; \\ Department of Infectious Diseases, Tropical Medicine \& AIDS, Academic Medical Center, University of Amsterdam, \\ Amsterdam, The Netherlands
}

\begin{abstract}
This study compared the costs and effects of insecticide (permethrin)-treated bed net (ITN) use in children less than five years of age in an area of intense, perennial malaria transmission in western Kenya. The data were derived from a group-randomized controlled trial of ITNs conducted between 1996 and 1999. The annual net cost per life-year gained was U.S. \$34 and the net annual cost per all-cause sick child clinic visit averted was U.S. \$49. After taking into account a community effect (protection from malaria afforded to non-ITN users who lived within 300 meters from users) these estimates decreased to U.S. \$25 and U.S. \$38, respectively. This study provides further evidence that ITNs are a highly cost-effective use of scarce health care resources.
\end{abstract}

\section{INTRODUCTION}

Randomized controlled trials in various malaria transmission settings have shown insecticide (permethrin)-treated bed nets (ITNs) to be effective in reducing child mortality. ${ }^{1-4}$ While there is a small but growing literature on the cost-effectiveness of ITNs, ${ }^{3,5-7}$ no information on cost-effectiveness in areas of intense, perennial malaria transmission is available. In addition, we know little about the extent to which the impact of ITNs on community members lacking ITNs (the mass effect ${ }^{8}$ or community effect ${ }^{9}$ ) influences estimates of cost-effectiveness. This economic evaluation is based upon the results of a community-based, group-randomized, controlled trial of ITNs in western Kenya conducted in an area of intense, perennial malaria transmission. This paper has two aims. The first is to evaluate the cost-effectiveness of ITNs in children less than five years of age using mortality and number of sick child visits to local health facilities as the key outcome variables. The second is to evaluate the impact on cost-effectiveness of the protection afforded to those who do not use ITNs who live in proximity ( $<300$ meters) to households with ITNs. In economic terminology, this community effect is a form of externality (Hanson K, Goodman C, Lines J, Meek S, Bradley D, Mills A, 2002. The Economics of Malaria Control. Malaria in Human Affairs: A collaboration between the Harvard University Center for International Development, the London School of Hygiene and Tropical Medicine and the World Bank: Roll Back Malaria, World Health Organization. http://mosquito.who.int/cmc_upload/0/ 000/015/605/ea_ch2.pdf.), but for the purposes of this paper and for consistency with other papers in this supplement, we will use the term community effect.

\section{MATERIALS AND METHODS}

ITN study. The group-randomized ITN study was conducted in a $500 \mathrm{~km}^{2}$ area of western Kenya in the contiguous sites of Asembo and Gem. Details of the study are reported elsewhere. ${ }^{10}$ The intervention was conducted from January 1997 to March 1999 in Asembo and from January 1998 to December 1999 in Gem. The primary objective of the study was to measure the effect of ITNs on all cause mortality of children 1-59 months of age. The study also estimated the effect of the intervention on all cause sick child visits (SCV) to local clinics (in Asembo only). To estimate the community effect of ITNs, epidemiologic data were linked to a base map generated using the global positioning system. ${ }^{9}$ Costs for the intervention were estimated from project expenditure records. Information on community costs was gathered through interviews with field staff and community members.

Resource use was categorized in accordance with three phases of the project: start-up, distribution, and insecticide treatment. In the start-up phase, meetings were held in each village to inform community members about the study rationale and design, and to provide an opportunity to ask questions. In the distribution phase, program staff distributed 45,667 polyester, 100-denier, 156-mesh bed nets, pre-treated with the target dose of $0.5 \mathrm{~g}$ of permethrin $/ \mathrm{m}^{2}$ of netting. This achieved an initial coverage ratio of 1.34 persons per ITN. The ITNs were distributed by project staff at central points in each village following a pre-arranged schedule. Each family was responsible for sending one representative to collect the nets and to receive training in how to hang them. Study staff later visited all the houses to ensure that ITNs were properly deployed. Re-treatment of nets with permethrin was scheduled every six months during the two-year intervention. Prior to each re-treatment exercise, villages were notified in advance of the day the ITNs were to be re-treated. Program staff visited each compound and re-treated the nets with the help of community members, who provided water and labor.

Methods for the economic evaluation. The framework for the economic evaluation (Table 1) was adapted from Drummond and others. ${ }^{11}$ Costs and effects for all parties affected by the intervention were included (i.e., users, community, and program providers). Both financial and economic costs were estimated. Research costs were not included. Financial costs represent funds paid for the implementation of the intervention by the project and are spread over a four-year period (1996-1999). Cost-effectiveness ratios are based on net (average) annual economic costs. It is not uncommon in ITN trials for the effectiveness data and cost estimates to be spread over different time periods. ${ }^{6,12}$ In this study, costs covered a four-year period and effects were measured over a 
TABLE 1

Description of measures of costs and effects

Costs
Financial cost of the program (i.e., funds paid out for the program
by the project)
Economic cost of the program (i.e., costs borne by the project and
community)
Individual and community health effects
Number of all-cause sick child visits averted
Deaths averted
Resource savings
Resource savings to the health sector
Resource savings to households and the community

two-year period (two years in Asembo and two years in Gem). The method used to measure and value capital costs involved annuitizing the initial capital cost over the useful life of each asset; that is, an equivalent annual cost has been estimated that is then added to the annual recurrent estimate. ${ }^{11}$ This process reflects the value-in-use of capital terms, rather than reflecting when the item was purchased. Economic costs differ from financial costs in two respects: an equivalent annual capital cost has been calculated and the value of community labor included. ${ }^{6}$ This was done to more accurately reflect the opportunity cost of resource use. Financial costs and economic costs are converted to U.S. dollars at the prevailing rate of exchange and deflated to 1996 values using the U.S. gross domestic product deflator. The official exchange rate at that time (1 U.S. $\$=78$ Kenyan Shillings) was assumed to reflect the scarcity of foreign exchange.

For each phase of the program, costs were separated into capital and recurrent costs. The recurrent costs borne by the providers were insecticides, detergent, personnel, office supplies and services, and transport. The community recurrent costs included water, transport, and the time spent washing, drying, and re-deploying the ITNs. Capital costs, all incurred by the provider, included bed nets, vehicles, buildings, office equipment, furniture, and supplies for impregnation. The total annual cost of the ITN program was obtained by summing the provider and community costs (both recurrent and capital).

Costs for project personnel, consumables, and transport were valued using current market rates. The insecticide was valued at the duty-free purchase price; the effect of variation in insecticide price was evaluated in the sensitivity analysis. Project personnel were valued according to existing salary scales. The difference in salaries of local and expatriate staff was accepted on the basis that the opportunity cost of expatriates was higher because of easier access to international labor markets. ${ }^{6}$ The community members who washed and re-deployed the nets did not receive a formal wage. Their time was valued using the estimated daily wage for a farm worker (US $\$ 1.30$ per day). The effect on net annual costs of varying the value of unwaged time and the number of senior staff salaries was also evaluated in the sensitivity analysis.

The costs of vehicles and equipment were annuitized over an expected life of 10 years and at a discount rate of $3 \%$. ITNs were treated as a capital item and converted to an annual equivalent cost assuming a 5-year life span and a 3\% discount rate. The effect on total costs of varying the discount rate was also tested.

Effectiveness. Three measures of effectiveness were calculated. First, the number of all-cause child deaths prevented by
ITN use was estimated. ${ }^{13}$ Second, life-years gained (LYG) were estimated by applying life expectancy at mean age of death of trial participants to deaths averted. A 3\% discount rate was then applied to derive an estimate of discounted life-years gained (DLYG). ${ }^{5}$ Third, morbidity was measured in terms of the number of all-cause sick child clinic visits averted. ${ }^{14}$ The effect of ITNs on all-cause mortality was apparent only in infants 1-11 months of age, but all children less than five years of age benefited from reduced morbidity. ${ }^{13,14}$ Since an impact on both child morbidity and mortality was observed in compounds lacking ITNs located within 300 meters of intervention villages, estimates of effectiveness with and without this community effect have been calculated. A detailed description of efficacy measures including spatial analyses and the effect of ITNs on nearby compounds lacking ITNs are reported in detail elsewhere. ${ }^{9,13,14}$

Resource savings. Resource savings to the health sector and households were also measured. Savings to the health sector were based on the potential reduction in health service use as measured by the difference in the absolute number of all-cause sick child clinic visits to local health centers averted by ITNs. ${ }^{14}$ The potential saving to the clinic was based on an estimate of the cost of drugs prescribed by clinic staff to sick children $\leq 59$ months of age. These drugs, when available, are normally provided free of charge by government clinics for this age group, and non-dispensing thus provides a direct saving to the clinic. An estimate of the drug costs was obtained from a previous study conducted in similar peripheral health facilities in a neighboring province (U.S. \$0.44 [1996 U.S. \$] per child per visit). ${ }^{15} \mathrm{We}$ assumed that a reduction in sick child visits would not result in a reduction in the infrastructural costs (e.g., maintenance and salary costs) of the clinic in the short term.

At the household level, saved treatment costs and the economic benefit of postponed funeral expenses were calculated. Health care expenses were assessed during a series of crosssectional surveys ${ }^{16}$ and broken down into five categories paid by the household for treating children less than five years of age: medicines; doctor or clinic fees; laboratory (e.g., needles, syringes, and tests); traditional healer (for fees, herbs, etc.); and other items such as food and travel costs associated with obtaining health care. ${ }^{17}$ It is important to note that funeral costs can be a serious economic burden to poor families. It is therefore relevant in such contexts to estimate the economic benefit associated with delaying funeral payment. Based upon an informal survey among local residents, funeral costs were estimated to be approximately $\$ 100$ per funeral. This consisted primarily of the cost of the coffin and other costs of arranging the funeral, which may include providing meals for numerous guests over a period of several days. The effect on net annual costs of lowering funeral costs by $50 \%$ and of varying the discount rate was tested in the sensitivity analysis.

Methods of analysis. Six cost-effectiveness ratios were calculated: 1) cost per child death averted; 2) cost per LYG;3) cost per DLYG; 4) cost per SCV averted; 5) cost per person protected; and 6) cost per ITN. In addition, net costeffectiveness ratios were calculated by subtracting resources saved from the total economic cost divided by the relevant outcome measure. Two sets of net cost-effectiveness ratios were calculated: those that did not account for the community effect, and those that did. 
TABLE 2

Financial costs (US \$1996) associated with the implementation of the intervention by the program*

\begin{tabular}{|c|c|c|c|c|c|c|}
\hline Item & 1996 & 1997 & 1998 & 1999 & Total & Cost profile (\%) \\
\hline \multicolumn{7}{|l|}{ Capital costs } \\
\hline Vehicles (4) & 80,000 & & & & 80,000 & 11 \\
\hline Furniture/equipment & 10,000 & & & & 10,000 & 1 \\
\hline ITNs & 92,000 & 138,000 & & & 230,000 & 31 \\
\hline Subtotal & 182,000 & 138,000 & & & 320,000 & 43 \\
\hline \multicolumn{7}{|l|}{ Recurrent (direct) costs } \\
\hline Permethrin & & 22,080 & 33,120 & & 55,200 & 8 \\
\hline Staff & 25,000 & 60,000 & 80,000 & 60,000 & 225,000 & 31 \\
\hline Fuel/maintenance & 10,000 & 15,000 & 24,000 & 20,000 & 69,000 & 10 \\
\hline Office rental & 1,000 & 1,000 & 1,500 & 1,000 & 4,500 & 1 \\
\hline Training & 5,000 & 5,000 & & & 10,000 & 1 \\
\hline Supplies & 10,000 & 10,000 & 12,000 & 10,000 & 42,000 & 6 \\
\hline Subtotal & 51,000 & 113,080 & 150,620 & 91,000 & 405,700 & 57 \\
\hline Total & 233,000 & 251,080 & 150,620 & 91,000 & 725,700 & 100 \\
\hline
\end{tabular}

* ITNs $=$ insecticide-treated bed nets.

The sensitivity of our results to variation in the discount rate was examined by increasing the rate to $6 \%$ and to $10 \% .5,7$ The effect on net annual costs of reducing the frequency of re-treating ITNs from twice a year to once a year was also determined. ${ }^{12}$ The cost of insecticide was reduced by $20 \%$ to reflect the possibility of using cheaper insecticides in the future $^{5,18}$ The cost of insecticide was also increased by $20 \%$ to explore the effect of using duty-free prices. Since it is likely that fewer senior staff salaries would be required in a nonresearch setting, the effect of a $50 \%$ reduction in staff salaries has been calculated. Finally, the effect of varying the value of the time of community members who washed and redeployed the ITNs as well as a reduction in funeral costs was estimated.

\section{RESULTS}

Total financial costs. The capital and recurrent financial costs of the intervention in local currency, excluding research costs, are shown in Table 2. The total financial cost of the program was U.S. $\$ 725,700$. Recurrent costs were $57 \%$ of total program costs. Staff salaries represented the largest recurrent cost item at $31 \%$. Insecticide (permethrin) represented $8 \%$ of total recurrent costs. A total of 45,667 ITNs were distributed. The annual capital cost of the program was U.S. $\$ 320,000$, with ITNs being the main capital item at U.S. $\$ 230,000$.

Total economic costs. The annual economic cost of the program was U.S. $\$ 148,856$ (Table 3). The key differences between Tables 2 and 3 is that for the latter, the imputed value of user labor is included and capital costs have been annuitized to provide an equivalent annual cost. Approximately $25 \%$ of annual economic costs were attributed to program start-up $(\$ 37,214), 40 \%$ to ITN distribution $(\$ 59,542)$, and $35 \%$ to retreatment $(\$ 52,100)$. The ITNs represented an average annual cost of U.S. $\$ 60,193(40 \%)$ and insecticide represented a cost of U.S. $\$ 13,707(9 \%)$.

Effectiveness and resource savings. We report elsewhere that ITNs were associated with a $27 \%$ reduction in the number of sick child (less than five years old) visits to local health facilities. ${ }^{14}$ This translates to an annual reduction of 2,025 visits per year in a population of 9,375 children less than five years old, or 2,328 visits when the community effect is taken into account. Based on a protective efficacy estimate of
$23 \%,{ }^{13}$ ITNs were also predicted to reduce all-cause postneonatal mortality by 61 deaths per year in the same population (2,005 infants 1-11 months old), or 73 deaths when additional benefits to the community are accounted for (Table 4).

The reduced number of clinic visits results in an annual saving to the health services of U.S. $\$ 891$ (U.S. $\$ 0.44$ per visit), or U.S. $\$ 1,024$ when adjusting for the community effect (Table 4). Households in ITN villages spent approximately U.S. $\$ 6.5$ per year less on health care for sick children less than five years old compared with those in the control villages. ${ }^{17}$ There were approximately 6,700 households with children in this age range in the ITN villages in Asembo and Gem, and 8,241 households if the communities located within 300 meters from ITN villages were also included. This represents an annual cost saving of U.S. $\$ 43,550$, or $\$ 53,567$ after adjusting for the community effect. Savings also accrued to households in the form of postponed funeral expenses with an average discounted saving of $\$ 77$ per year. When we adjusted for the community effect, annual direct resource savings to the community amounted to $\$ 5,621$. These estimates are based on 1) an average life expectancy at birth of 49 years; ${ }^{19}$

TABLE 3

Annual economic cost*

\begin{tabular}{lrr}
\hline \multicolumn{1}{c}{ Item } & $\begin{array}{c}\text { Average annual equivalent } \\
\text { cost }(1996 \$)\end{array}$ & $\begin{array}{c}\text { Cost } \\
\text { profile }(\%)\end{array}$ \\
\hline Program capital costs & & \\
ITNs & 60,193 & 40.4 \\
Vehicles & 9,378 & 6.3 \\
Equipment & 1,172 & 0.8 \\
Subtotal & 70,743 & 47.5 \\
Program recurrent costs & & \\
Insecticide & 13,707 & 9.2 \\
Staff & 31,311 & 21.0 \\
Fuel/maintenance & 16,805 & 11.3 \\
Office rental & 1,100 & 0.7 \\
Training & 2,479 & 1.7 \\
Supplies & 10,266 & 6.9 \\
Subtotal & 75,668 & 50.8 \\
User/community recurrent costs & & \\
Water & 845 & 0.6 \\
Transport & 500 & 0.3 \\
Time/Labor & 1,100 & 0.7 \\
Subtotal & 2,445 & 1.6 \\
Total & 148,856 & 100 \\
\hline * ITNs = insecticide-treated bed nets. & &
\end{tabular}


TABLE 4

Summary of costs, effects, and cost-effectiveness*

\begin{tabular}{|c|c|c|}
\hline & $\begin{array}{l}\text { Community } \\
\text { effect not } \\
\text { included }\end{array}$ & $\begin{array}{c}\begin{array}{c}\text { Community } \\
\text { effect } \\
\text { included }\end{array} \\
\text { ind }\end{array}$ \\
\hline \multicolumn{3}{|l|}{ Costs } \\
\hline Annual economic cost of ITN program & 148,856 & 148,856 \\
\hline Annual cost savings (see Results) & $-49,138$ & $-60,212$ \\
\hline Net annual cost & 99,718 & 88,644 \\
\hline \multicolumn{3}{|l|}{ Effects (per year) } \\
\hline Number of persons protected & 62,500 & 62,500 \\
\hline $\begin{array}{l}\text { Number of all-cause child deaths (1-11 } \\
\text { months old) averted }\end{array}$ & 61 & 73 \\
\hline Life-years gained (LYG) & 2,959 & 3,540 \\
\hline $\begin{array}{l}\text { Discounted life-years gained (DLYG) } \\
\text { at } 3 \%\end{array}$ & 1,525 & 1,825 \\
\hline $\begin{array}{l}\text { Number of all-cause sick child visits } \\
(<5 \text { years }) \text { averted }\end{array}$ & 2,025 & 2,328 \\
\hline Number of ITNs & 45,667 & 45,667 \\
\hline \multicolumn{3}{|l|}{ Resource savings } \\
\hline $\begin{array}{l}\text { Community: discounted funeral } \\
\text { expenses }\end{array}$ & 4,697 & 5,621 \\
\hline $\begin{array}{l}\text { Community: reduced expenditure on } \\
\text { treating ill children }\end{array}$ & 43,550 & 53,567 \\
\hline $\begin{array}{l}\text { Health service: reduced expenditure on } \\
\text { health center visits }\end{array}$ & 891 & 1,024 \\
\hline \multicolumn{3}{|l|}{ Cost-effectiveness } \\
\hline Net cost per person protected & 1.6 & 1.4 \\
\hline $\begin{array}{l}\text { Net cost per all-cause child death } \\
\text { averted }\end{array}$ & 1,635 & 1,214 \\
\hline Net cost per LYG & 34 & 25 \\
\hline Net cost per DLYG at $3 \%$ & 65 & 49 \\
\hline $\begin{array}{l}\text { Net cost per all-cause sick child visit } \\
\text { averted }\end{array}$ & 49 & 38 \\
\hline Net cost per ITN & 2.2 & 1.9 \\
\hline
\end{tabular}

2) a discount rate of $3 \% ; 3$ ) an estimated reduction in total number of post-neonatal deaths (age $=1-11$ months) by 73 ; and 4) and an average cost per funeral of U.S. \$100. This figure was U.S. $\$ 4,697$ if the community effect was not taken into account (Table 4).

Cost-effectiveness. Table 4 also shows the cost-effectiveness ratios both adjusted and unadjusted for the community effect. Approximately 62,500 adults and children were protected by the intervention at an estimated economic cost of U.S. $\$ 1.4$ per person protected per year (U.S. \$1.6 unadjusted). Among the children 1-11 months of age, 3,540 lifeyears of protection were achieved at the end of the first year at a cost of U.S. \$25 per infant (U.S. \$34 unadjusted). This is based on an estimate of 48.5 life-years gained at the median age of death (six months) of trial infants (48.5 life-years gained $\times 73$ deaths averted $=3,540$ life-years of protection). A total of 73 child deaths were prevented by the use of ITNs at an annual cost of U.S. \$1,214 per death averted (U.S. $\$ 1,635$ unadjusted). Applying a discount rate of $3 \%,{ }^{3}$ each death prevented was equivalent to approximately 25 DLYG or a total of 1,825 life-years of protection. This represented an estimated cost of U.S. \$49 per DLYG (U.S. \$65 unadjusted). The annual net cost per SCV averted is U.S. \$38 (U.S. \$49 unadjusted) or U.S. \$1.9 per ITN (U.S. \$2.2 unadjusted).

Sensitivity analysis. The sensitivity of net annual costs to changes in the discount rate, frequency of net impregnation, cost of insecticide and salary, or wage levels is shown in Table 5. While this analysis includes the community effect, the estimated changes in total cost are the same or within 1-3 per-
TABLE 5

Effect of sensitivity analysis on net annual economic costs*

\begin{tabular}{|c|c|}
\hline Variable & Effect on total economic cost \\
\hline $\begin{array}{l}\text { Discount rate (applied } \\
\text { to capital and } \\
\text { funeral costs) }\end{array}$ & $\begin{array}{l}\text { Increasing the discount rate of } 3 \% \\
\text { to } 6 \% \text { and from } 3 \% \text { to } 10 \% \text { would } \\
\text { increase the cost of the interven- } \\
\text { tion by } 4 \% \text { and } 11 \% \text {, respectively }\end{array}$ \\
\hline $\begin{array}{l}\text { Frequency of net } \\
\text { impregnation }\end{array}$ & $\begin{array}{l}\text { Reducing the frequency of net im- } \\
\text { pregnation to once a year reduces } \\
\text { total costs by } 29 \%\end{array}$ \\
\hline Cost of insecticide & $\begin{array}{l}\text { A } 20 \% \text { reduction (or increase) in } \\
\text { the cost of insecticide reduces (or } \\
\text { increases) total costs by } 3 \%\end{array}$ \\
\hline $\begin{array}{l}\text { Frequency of net } \\
\text { impregnation and } \\
\text { cost of insecticide }\end{array}$ & $\begin{array}{l}\text { Reducing net impregnation to once a } \\
\text { year and reducing the cost of in- } \\
\text { secticide by } 20 \% \text { reduces total } \\
\text { costs by } 30 \%\end{array}$ \\
\hline Unwaged labor & $\begin{array}{l}\text { Valuing unwaged time at } 25 \% \text { above } \\
\text { and } 25 \% \text { below } \$ 1.30 \text { per day } \\
\text { leads to a } 0.3 \% \text { change in total } \\
\text { costs }\end{array}$ \\
\hline Wages of program staff & $\begin{array}{l}\text { A } 50 \% \text { reduction (or increase) in } \\
\text { salaries would decrease (or in- } \\
\text { crease) total costs by } 17 \%\end{array}$ \\
\hline Funeral costs & $\begin{array}{l}\text { A } 50 \% \text { reduction in funeral costs } \\
\text { results in a } 3 \% \text { reduction in total } \\
\text { costs }\end{array}$ \\
\hline
\end{tabular}

centage points of the estimates generated using the unadjusted figures. Increasing the discount rate applied to both capital and funeral costs from $3 \%$ to $6 \%$ or from $3 \%$ to $10 \%$ would increase the cost of the intervention by approximately $4 \%$ and $11 \%$, respectively. The cost per child death averted would then increase from U.S. $\$ 1,214$ to U.S. $\$ 1,265$ or U.S. $\$ 1,354$.

Reducing the frequency of bed net re-treatment to once a year also reduced the cost of the intervention by an estimated $29 \%$ with a concomitant reduction in the cost per child death averted from U.S. $\$ 1,214$ to U.S. \$857. A decrease in the cost of insecticide of $20 \%$ led to a reduction in the cost per child death averted from U.S. $\$ 1,214$ to U.S. $\$ 1,176$ (or in the case of a $20 \%$ increase in insecticide, U.S. $\$ 1,252$ ), representing a mere $3 \%$ change in cost. If a $20 \%$ lower cost of insecticide is combined with yearly re-treatment, costs are reduced by $30 \%$ and the cost per child death averted decreases from U.S. $\$ 1,214$ to U.S. $\$ 839$.

The effect of valuing unwaged time at $25 \%$ above or $25 \%$ below $\$ 1.30$ per day changed costs by only $0.3 \%$. However, costs were reduced by $17 \%$ to $\$ 72,988$ per annum by a $50 \%$ reduction in senior staff salaries. A $50 \%$ decrease in funeral costs was associated with a $3 \%$ reduction in costs.

In a separate analysis of effects, the discount rate applied to life-years gained varied from $3 \%$ to $6 \%$ and from $3 \%$ to $10 \%$. This led to an increase in the net cost per discounted life-year gained from $\$ 49$ to $\$ 76$ and $\$ 121$, respectively.

\section{DISCUSSION}

Several studies have shown that ITNs are a cost-effective malaria control intervention in African communities. ${ }^{20-22}$ This study provides the first evidence that the costeffectiveness of the intervention in areas with intense, perennial malaria transmission is comparable to that found in other 
epidemiologic settings. The net cost-effectiveness estimates reported in this study, U.S. \$25 per LYG and \$1,214 per death averted, fall well within the range of previously reported estimates. ${ }^{20}$ For example, estimates from The Gambia, where bed net use was high and only insecticides had to be provided, indicate a gross cost per death averted of U.S. $\$ 219^{6}$ and U.S. $\$ 665$. At the other end of the range are estimates of $\$ 2,003$ and $\$ 2,958$ for Ghana ${ }^{5}$ and coastal Kenya, ${ }^{23}$ respectively. In these latter two areas, as is the case in western Kenya, initial bednet coverage was low so both bed nets and insecticide had to be provided. A number of factors make it difficult to compare the cost-effectiveness of ITNs with other malaria control interventions, most notably, the small evidence base and the variety of assumptions underlying the different analyses. Nonetheless, analyses such as this one would indicate that ITNs are cost-effective according to the guideline that any intervention with a cost per DLYG less than $\$ 150$ may be considered an attractive use of scarce health care resources in low-income countries. ${ }^{24}$

This study also demonstrates that estimates of costeffectiveness are markedly affected when effects of ITNs on those lacking ITNs are taken into account. Taking beneficial effects in this larger population into account resulted in a decrease in cost-effectiveness ratios by about one-fourth. The annual net cost per LYG decreased from U.S. \$34 to U.S. \$25 after adjusting for the community effects of ITNs. Similarly, the net annual cost per SCV averted decreased from U.S. $\$ 49$ to U.S. $\$ 38$ after adjusting for this effect. It is important to note that the magnitude of the community health effects will be influenced by population density in areas neighboring intervention zones. Such effects may be less relevant to islands or isolated refugee camps where proximate fringe populations may not exist. In contrast, it is possible that the community effect might be stronger in areas where the absolute population density is higher than that of the relatively dispersed western Kenya population.

The estimate of community effects and their inclusion in economic analyses raises a number of important issues for debate. In economic terms, this community effect is a positive externality. In making their choices, individuals will not necessarily take into account these additional positive effects and may consume less than the socially optimal amount, which is the amount that would be consumed if markets prices existed for these effects. Focusing government intervention on the alleviation of this form of market failure overlooks factors that influence the willingness and ability of health care providers to distribute nets solely on the basis of maximizing efficiency. There may be compelling ethical and social reasons why those responsible for the delivery of ITNs choose to target certain groups of individuals or to consider a policy of complete coverage. Much will depend on the resources available and on the equity and efficiency goals of local and international decision-makers.

In addition, cost-effectiveness depends upon several interacting factors including the definition and measurement of resource savings. In this study, we estimated resource savings in three different ways (i.e., direct savings to the health sector and both direct and indirect savings to the community), allowing us to calculate net, rather than gross costeffectiveness ratios. Resource savings (without adjustment for the community effect) were $33 \%$ of total costs. Most of these savings resulted from accumulated small reductions in community-borne costs for treating sick children. At the community level this form of saving might be viewed as negligible ( $\$ 6.50$ per household per year), ${ }^{17}$ but the overall effect on the adjustment of gross cost-effectiveness ratios was substantial.

As for most economic evaluations of ITN programs, our analysis used permethrin as the insecticide. In recent years, other synthetic pyrethroids have entered the market, which are both cheaper and longer lasting. Our sensitivity analysis indicated that replacement of permethrin with an insecticide $20 \%$ lower in cost requiring only yearly application would result in a $30 \%$ lower cost-effectiveness ratio. The results of similar sensitivity analyses conducted in other studies are consistent with this finding. ${ }^{6,7}$ However, it should be noted that re-treatment annually, as opposed to every six months, might result in lower levels of effectiveness. If this is the case, then any reduction in cost may be counter balanced by a reduction in effectiveness.

Details of delivery mechanisms will also impact upon costeffectiveness. ${ }^{25,26}$ In a recent study in Kenya, re-treatment levels of a bi-annual house-to-house re-treatment schedule provided free of charge were compared with a social marketing approach that introduced cost-retrieval. The free retreatment service achieved re-treatment levels between $61 \%$ and $67 \%$, while the social marketing approach yielded a very low re-treatment rate of $7 \% .{ }^{26}$ In our study, project staff were mainly responsible for bed net re-treatment. While no fee was charged for this service, it is important to recognize that financial constraints may lead to cost recovery measures which in turn impact on levels of coverage and adherence.

Finally, the cost-effectiveness analyses of efficacy trials may not reflect operational settings. Trial participants may be more likely to exhibit higher levels of adherence than those in programmatic settings. Evans and others ${ }^{26}$ illustrated the significant effect the level of adherence has on cost-effectiveness estimates. However, relative effects of coverage and adherence are difficult to judge because infants not sleeping under ITNs may still benefit from having an ITN in the house, or as was demonstrated in this trial, having ITNs in many proximate houses. Moreover, this study focused on two groups, those with nets and those without. In practice, however, some families may already own a net and comparisons of cost and effect would ideally be made across each of these groups. Also the levels of cost-effectiveness described in this study and, in particular, the positive benefits to non-users, rely on the distribution of nets by randomized lottery. In practice, different methods of distribution are likely to be used. These variations in distribution are also expected to impact upon estimates of both cost and effect.

In agreement with the findings of previous efficacy trialbased modeling studies, our results show that ITNs are a highly cost-effective use of scarce health care resources. However, there are a number of important ways in which our results contribute to the existing knowledge base and stimulate debate. This study provides much needed information on the cost-effectiveness of ITNs in areas of intense, perennial malaria transmission. Cost savings to both the community and to the health sector were also measured to allow for the estimation of net cost-effectiveness ratios. Few studies have taken these potential savings from ITN use into account. ${ }^{5}$ Comparisons were also made across cost-effectiveness ratios 
that include a community effect and those that do not. While some of the policy implications of using these different sets of estimates to inform resource allocation have been raised, this complex issue deserves greater attention by researchers. These findings must also ultimately be balanced against measures of affordability and the operational challenges of maximizing levels of coverage, insecticide treatment, and adherence.

Acknowledgments: We express our gratitude to the children and caregivers who participated in the study and the many people that assisted with this project. We thank Dr. Stephen Jan, Dr. Julia FoxRushby, and an anonymous referee for their helpful comments. We also thank the Director of the Kenya Medical Research Institute for his permission to publish this work.

Financial support: The ITN project was funded by the United States Agency for International Development. Virginia Wiseman was supported by the Gates Malaria Partnership of The London School of Hygiene and Tropical Medicine. Feiko O. ter Kuile was partly supported by a grant from the Netherlands Foundation for the Advancement of Tropical Research (WOTRO) (The Hague, The Netherlands).

Disclaimer: The opinions or assertions contained in this manuscript are the private ones of the authors and are not to be construed as official or reflecting the views of the U.S. Public Health Service or Department of Health and Human Services. Use of trade names is for identification only and does not imply endorsement by the U.S. Public Health Service or Department of Health and Human Services.

Authors' addresses: Virginia Wiseman and Anne J. Mills, Health Economics and Financing Programme \& Gates Malaria Partnership, London School of Hygiene and Tropical Medicine, 50 Bedford Square, London WC1B 3DP, United Kingdom. William A. Hawley, Feiko O. ter Kuile, and Penelope A. Phillips-Howard, Division of Parasitic Diseases, National Center for Infectious Diseases, Centers for Disease Control and Prevention, Mailstop F-22, 4770 Buford Highway, Atlanta, GA 30341. John M. Vulule, Centre for Vector Biology and Control Research, Kenya Medical Research Institute, PO Box 1578, Kisumu, Kenya. Bernard L. Nahlen, Roll Back Malaria, World Health Organization, Avenue Appia 20, 1211 Geneva 27, Switzerland.

\section{REFERENCES}

1. D'Alessandro U, Olaleye BO, McGuire W, Langerock P, Bennett S, Aikins MK, Thomson MC, Cham MK, Cham BA, Greenwood BM, 1995. Mortality and morbidity from malaria in Gambian children after introduction of an impregnated bednet programme. Lancet 345: 479-483.

2. Nevill CG, Some ES, Mung'ala VO, Mutemi W, New L, Marsh K, Lengeler C, Snow RW, 1996. Insecticide-treated bednets reduce mortality and severe morbidity from malaria among children on the Kenyan coast. Trop Med Int Health 1: 139-146.

3. Binka FN, Kubaje A, Adjuik M, Williams LA, Lengeler C, Maude GH, Armah GE, Kajihara B, Adiamah JH, Smith P, 1996. Impact of permethrin impregnated bednets on child mortality in Kassena-Nankana district, Ghana: a randomized controlled trial. Trop Med Int Health 1: 147-154.

4. Habluetzel A, Diallo DA, Esposito F, Lamizana L, Pagnoni F, Lengeler C, Traore C, Cousens SN, 1997. Do insecticidetreated curtains reduce all-cause child mortality in Burkina Faso? Trop Med Int Health 2: 855-862.

5. Binka FN, Mensah OA, Mills A, 1997. The cost-effectiveness of permethrin impregnated bednets in preventing child mortality in Kassena-Nankana district of northern Ghana. Health Policy 41: 229-239.

6. Picard J, Aikins M, Alonso PL, Armstrong Schellenberg JR, Greenwood BM, Mills A, 1993. A malaria control trial using insecticide-treated bed nets and targeted chemoprophylaxis in a rural area of The Gambia, west Africa. 8. Cost-effectiveness of bed net impregnation alone or combined with chemopro- phylaxis in preventing mortality and morbidity from malaria in Gambian children. Trans R Soc Trop Med Hyg 87 (Suppl 2): $53-57$.

7. Aikins MK, Fox-Rushby J, D'Alessandro U, Langerock P, Cham K, New L, Bennett S, Greenwood B, Mills A, 1998. The Gambian National Impregnated Bednet Programme: costs, consequences and net cost-effectiveness. Soc Sci Med 46: 181-191.

8. Ilboudo-Sanogo E, Cuzin-Ouattara N, Diallo DA, Cousens SN, Esposito F, Habluetzel A, Sanon S, Ouedraogo AP, 2001. Insecticide-treated materials, mosquito adaptation and mass effect: entomological observations after five years of vector control in Burkina Faso. Trans R Soc Trop Med Hyg 95: 353-360.

9. Hawley WA, Phillips-Howard PA, ter Kuile FO, Terlouw DJ, Vulule JM, Ombok M, Nahlen BL, Gimnig JE, Kariuki SK, Kolczak MS, Hightower AW, 2003. Community-wide effects of permethrin-treated bed nets on child mortality and malaria morbidity in western Kenya. Am J Trop Med Hyg 68 (Suppl 4): 121-127.

10. Phillips-Howard PA, ter Kuile FO, Nahlen BL, Alaii JA, Gimnig JE, Kolczak MS, Terlouw DJ, Kariuki SK, Shi YP, Kachur SP, Hightower AW, Vulule JM, Hawley WA, 2003. The efficacy of permethrin-treated bed nets on child mortality and morbidity in western Kenya. II. Study design and methods. Am J Trop Med Hyg 68 (Suppl 4): 10-15.

11. Drummond M, O'Brien B, Stoddart G, Torrance G, 1997. Methods for the Economic Evaluation of Health Care Programs. New York: Oxford University Press.

12. Walker D, Kumaranayake L, 2002. Allowing for differential timing in cost analyses: discounting and annualization. Health Policy Plan 17: 112-118.

13. Phillips-Howard PA, Nahlen BL, Kolczak MS, Hightower AW, ter Kuile FO, Alaii JA, Gimnig JE, Arudo J, Vulule JM, Odhacha A, Kachur SP, Schoute E, Rosen DH, Sexton JD, Oloo AJ, Hawley WA, 2003. Efficacy of permethrin-treated bed nets in the prevention of mortality in young children in an area of high perennial malaria transmission in western Kenya. Am $J$ Trop Med Hyg 68 (Suppl 4): 23-29.

14. Phillips-Howard PA, Nahlen BL, Wannemuehler KA, Kolczak MS, ter Kuile FO, Gimnig JE, Alaii JA, Odacha A, Vulule JM, Hawley WA, 2003. Impact of permethrin-treated bed nets on the incidence of sick child visits to peripheral health facilities. Am J Trop Med Hyg 68 (Suppl 4): 38-43.

15. Boulanger LL, Lee LA, Odhacha A, 1999. Treatment in Kenyan rural health facilities: projected drug costs using the WHOUNICEF integrated management of childhood illness (IMCI) guidelines. Bull World Health Organ 77: 852-858.

16. ter Kuile FO, Terlouw DJ, Phillips-Howard PA, Hawley WA, Friedman JF, Kolczak MS, Kariuki SK, Shi YP, Kwena AM, Vulule JM, Nahlen BL, 2003. Impact of permethrin-treated bed nets on malaria and all-cause morbidity in young children in an area of intense perennial malaria transmission in western Kenya: cross-sectional survey. Am J Trop Med Hyg 68 (Suppl 4): $100-107$.

17. Meltzer MI, Terlouw DJ, Kolczak MS, Odhacha A, ter Kuile FO, Vulule JM, Alaii JA, Nahlen BL, Hawley WA, PhillipsHoward PA, 2003. The household level economics of using permethrin-treated bed nets to prevent malaria in children less than five years of age. Am J Trop Med Hyg 68 (Suppl 4): 149-160.

18. Luo D, Lu D, Yao R, Li P, Huo X, Li A, Wen L, Ge C, Zhang S, Huo H, 1994. Alphamethrin-impregnated bed nets for malaria and mosquito control in China. Trans $R$ Soc Trop Med Hyg 88: 625-628.

19. WHO Statistical Information System (WHOSIS), 2001. Evidence and Information for Health Policy: Burden of Disease Statistics. Geneva: World Health Organization.

20. Goodman C, Colemans P, Mills A, 2000. Economics of Malaria Control in Sub-Saharan Africa. Geneva: World Health Organization.

21. Goodman CA, Mills AJ, 1999. The evidence base on the costeffectiveness of malaria control measures in Africa. Health Policy Plan 14: 301-312.

22. Lengeler C, 2001. Comparison of malaria control interventions. Bull World Health Organ 79: 77.

23. Some ES, 1998. Optimizing the Community Effectiveness of In- 
secticide-Impregnated Bednets Used for Malaria Control in Coastal Kenya: Implications of Perceptions, Programme Organization, Compliance, and Costs. London: Department of Epidemiology and Population Health, London School of Hygiene and Tropical Medicine.

24. World Health Organization, 1996. Report of the Ad Hoc Committee on Health Research Relating to Future Intervention Op tions. TDR/Gen/96.1. Geneva: World Health Organization.
25. Snow RW, McCabe E, Mbogo CN, Molyneux CS, Some ES, Mung'ala VO, Nevill CG, 1999. The effect of delivery mechanisms on the uptake of bed net re- impregnation in Kilifi District, Kenya. Health Policy Plan 14: 18-25.

26. Evans DB, Azene G, Kirigia J, 1997. Should governments subsidize the use of insecticide-impregnated mosquito nets in Africa? Implications of a cost-effectiveness analysis. Health Policy Plan 12: 107-114. 